\title{
The Role of Insulin-Like Growth Factor 1 in the Development of Benign and Malignant Thyroid Nodules
}

\author{
Engin Baştürk, Metin Kement, Dilek Yavuzer, Selahattin Vural, Cem Gezen, Hülya llıksu Gözü, Ayşe Karadayı, Mustafa Öncel
}

Department of $1^{\text {st }}$ General Surgery, Kartal Training and Research Hospital, istanbul, Turkey

\begin{abstract}
Objective: This study aims to investigate the role of IGF-1 in the development of nodular thyroid disease.
\end{abstract}

Material and Methods: A total number of 100 consecutive patients operated for nodular thyroid disease in our institution were included in this prospective study. In addition to classical pathological examinations, nodules and extranodular healthy tissues were sampled and immunochemically stained for IGF-1. The materials were independently evaluated using an Allred Scoring System ranging from 0 to 8 . If the score was $\geq 1$, the tissue was accepted as IGF-1 positive.

Results: IGF-1 positivity was observed in $88 \%$ and $58 \%$ of the samples obtained from nodules and extranodular healthy tissues, respectively. Allred 8 -unit scores were higher in benign nodules $(n=89 ; 4.1 \pm 2.3)$ and papillary carcinomas $(n=7 ; 6.7 \pm 1.3)$, than in extranodular healthy tissues in the same patients $(2.3 \pm 2.3$ and $3.3 \pm 1.9$, respectively); and higher in papillary carcinomas than in benign nodules, when the scores were compared to each other ( $p<0.01$ for all comparisons).

Conclusions: Allred 8-unit scores for IGF-1 increase in the presence of benign thyroid nodules, papillary cancer. The results of our study support the findings of previous studies demonstrating the role of IGF-1 in the development of thyroidal nodules.

Key Words: IGF-1, thyroid nodules, thyroid cancer

Received: 26.05.2011 Accepted: 14.10.2011

\section{Introduction}

Goiter is a non-specific term describing enlargement of the thyroid gland. Nearly all disorders of the thyroid result in some enlargement of the gland and the non-specific term 'goiter' embraces them all. Goiters can be classified as toxic or nontoxic, diffuse or nodular and nodules can be solitary or multiple. Many nodular goiters arise from simple diffuse goiters, especially if iodine intake or availability is compromised. The initially diffuse hyperplastic process then becomes localized to one or several areas of disorganized thyroid metabolism in which the hyperplastic acini undergo colloid involution, while others demonstrate cystic degeneration, hemorrhage, or necrosis. Some degree of nodular fibrosis and calcification may also be present and may determine macroscopic features of nodules. The prevalence of palpable thyroid nodules is $3 \%$ to $7 \%$ in North America and $10 \%$ to $30 \%$ in areas of endemic iodine deficiency, and the prevalence of thyroid nodules can reach as high as $50 \%$ based on ultrasonography (US) or autopsy data in even non endemic regions (1).

A significant number of patients with nodular thyroid glands develop thyrotoxicosis, and this progress is directly related to the duration of the goiter. The correlation between iodine intake and prevalence of nodular non-toxic nodular goiter can similarly be applied to toxic multinodular goiter. The status of TSH suppression in nodular goiter does not only mean clinical consequences of disease, it also indicates a crucial level of thyroid autonomy as well. Constitutive activation of the CAMP signaling pathway is widely accepted as the biochemical driving force of thyroid autonomy. This may be indicated by the presence of somatic activating TSH receptor (TSHR) mutations in scintigraphically non-suppressible areas in euthyroid goiters in iodine-deficient regions, or less frequently, by Gs protein mutations in macroscopic toxic thyroid nodules, both in solitary nodules (2).

The relationship of thyroid cancer with nodular goiter is still debated. Carcinomas may arise from a benign nodule while this must happen rarely and it is not the ordinary course of events. If carcinomas arise from benign nodules, it might be expected that the majority would be follicular rather than papillary, and this is not the case. Also, although carcinomas, papillary type mostly, occur in nontoxic nodular goiters with a reported frequency of $4-17 \%$ of cases, the age of diagnosis for papillary carcinomas does not follow that for nontoxic goiter $(3,4)$. Papillary carcinomas occur in children and adolescents, and reach their highest frequency during the middle 
decades of life. Multinodular goiter, by contrast, is infrequent in childhood, but increases with each decade. The high frequency of carcinomas detected in nodular goiter appears to reflect the effectiveness of selection of patients for operation on the basis of suspicious clinical signs in the gland. Although it remains unproven, it is likely that, in many or most thyroid nodules and carcinomas, one specific mutational event leads directly to the development of the specific neoplasm $(3,4)$.

Insulin like growth factor (IGF) has two types (1 and 2), and both were isolated and characterized in the 1970's (5). Body structures of the molecules are similar to that in insulin, and all are believed to derive from a common ancestral gene. However, in contrast to insulin, which acts as a catabolic hormone, IGFs promote proliferation, survival, and/or differentiation in the cellular basis. IGF-1 synthesis is regulated by growth hormone $(\mathrm{GH})(6)$. IGFs are shown to have a role in the development of a number of diseases including breast cancer (7).

The IGF-1 receptor and a variety of IGF-binding proteins (IGFBPs) are expressed in thyroid tissue (8). Thus, it may be possible that IGF may affect thyroid cells, and play a role in the development of thyroidal diseases. Studies have revealed that this molecule facilitates thyroid epithelium proliferation, induced by thyroid stimulating hormone in animal studies $(9,10)$. Increased expression of IGF-1 receptors has been documented in thyroid tissue in patients with Graves' disease and thyroid cancer $(11,12)$, and the relationship between the tissue and serum levels of IGF-1 and the development of multinodular goiter has also been shown $(13,14)$. Additionally, thyroid cancer has been reported as the most common cancer type in patients with acromegaly (15).

The link between IGF-1 and thyroidal diseases deserves to be extensively investigated. In addition, synchronized analysis of the diseased (nodules or cancer) and healthy tissues has never been evaluated. Thus, the current study aims to assess the tissue levels of IGF-1 in diseased (nodular) and healthy (extranodular) tissues in nodular thyroid disease, and inspect the link between IGF-1 and thyroid nodules.

\section{Material and Methods}

A total number of 100 consecutive patients who underwent total thyroidectomy for nodular thyroid disease in our institution between May and September 2007 were included in this prospective study. The study design was approved by the Institutional Education and Planning Committee, and written informed consent was obtained from all patients or from legal guardians for cases younger than 18 years of age.

All patients had routine preoperative evaluation including blood levels of hormones (free T3, free T4 and sensitive thyroid stimulating hormone [sTSH]), and thyroid ultrasound and scintigraphy. If active nodule(s) were present in the scintigraphic examination, the nodule(s) were defined as 'hot'. If a patient needed an anti-thyroid drug regime preoperatively due to elevated thyroid hormones, the status was called toxic nodular disease. Cases were excluded if they underwent a procedure less than total thyroidectomy (lobectomy, subtotal or nearly total thyroidectomy).
Specimens were immediately examined and fixed in $10 \%$ formaldehyde solution. Macroscopic features including size of the specimens and nodule(s) were recorded. The paraffin blocks were prepared using standard histological procedures. The sections of the samples were cut in $3 \mu \mathrm{m}$ thick and stained with Hemotoxilen-Eosin. Besides classical pathological examinations, the largest nodule was sectioned in $2 \mu \mathrm{m}$ thick samples and immunochemically stained with an IGF-1 specific material ( $\mathrm{H}-70$, sc-9013 rabbit polyclonal antibody dilution 1:200; Santa Cruz Biotechnology, Santa Cruz, CA) following the manufacturer's instructions. Similarly, healthy tissues far from the primary nodules were sampled (extranodular sampling) and stained for a possible IGF-1 positivity using the same technique in all patients. The materials were independently evaluated by two experienced pathologists using a semi-quantitative scoring system (Allred 8-unit Scoring System) ranging from 0 to 8 (16). In case of a disparity in scores between two clinicians, they discussed and came to an agreement. If the score was $\geq 1$, the tissue was accepted as IGF-1 positive. The IGF-1 positivity rates and scores were compared between healthy and pathologic tissues, and between different pathological diagnoses.

\section{Allred 8-unit scoring system (16)}

This system evaluates the proportion and intensity of the IGF-1 staining. The proportion score represents the estimated fraction of positive staining cell nuclei $(0=$ none; $1=$ less than one hundredth; $2=$ one hundredth to one tenth; $3=$ one tenth to one third; $4=$ one third to two thirds; $5=$ greater than two thirds). The intensity score represents the estimated mean staining intensity of positive cell nuclei $(0=$ none; $1=$ weak; 2 =intermediate, $3=$ strong). Total score is expressed as the sum of the proportion and intensity scores (ranges from 0 to 8 ) (Figures 1, 2).

\section{Statistics analysis}

All statistical analyses were carried with SPSS for Windows 15.0. Descriptive statistics included mean and standard deviation for continuous variables and frequencies using percent for categorical variables. Student's t-test was used to determine whether the differences between the mean values of continuous variables based on weight were significantly different. The Chi-square test or Fisher exact test, if appropriate,

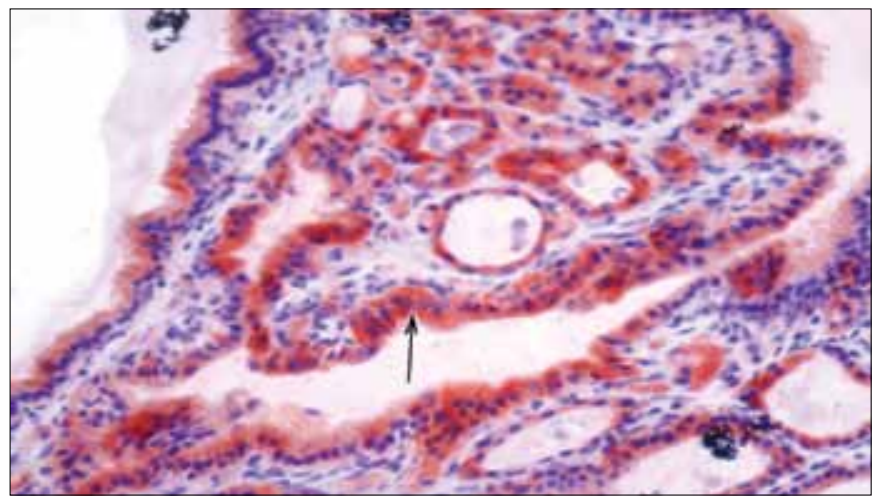

Figure 1. A colloidal nodule with IGF staining proportion score $=3$ and intensity score $=3$ (Allred Score=6) $(x 400)$ 
were performed to determine overall differences in frequencies of categorical variables among the groups and for pairwise comparisons of frequencies. The correlation between two continuous variables was studied with the Pearson's bivariate test. $p \leq 0.05$ was considered as statistically significant.

\section{Results}

A total number of 100 patients who underwent total thyroidectomy in our institution were enrolled in the study. There were $83(83 \%)$ females and the mean age ( \pm standard deviation) was $47.1 \pm 13.6$ years. IGF-1 positivity was detected in 88

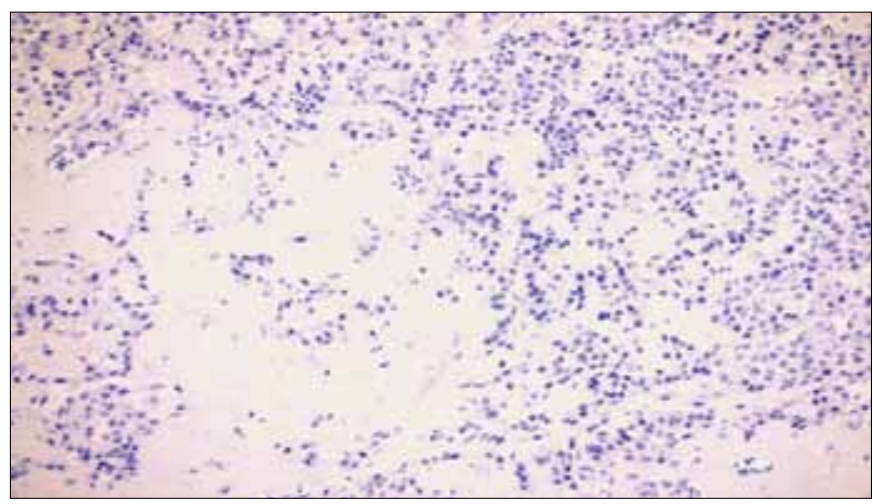

Figure 2. Medullary cancer with no IGF staining (Allred Sco$\mathrm{re}=0)(\mathrm{x} 200)$
(88\%) and 58 (58\%) of the samples obtained from nodules and extranodular healthy tissues, respectively. When demographic data were compared according to the findings in nodules; age $(47.8 \pm 13.9$ vs. $42.0 \pm 9.0$ years; $p=0.16)$ and gender $(73$ [86.9\%] vs.11 [91.7\%] females; $p=0.685)$ were similar in IGF-1 positive $(n=88)$ and negative cases $(n=12)$, respectively. Similarly, age $(46.2 \pm 15.3$ vs. $48.5 \pm 10.7$ years; $p=0.405)$ and gender (51 [87.9\%] vs. 38 [90.5\%] females) IGF-1 positive $(n=58)$ and negative $(n=42)$ patients, respectively, were not statistically different, when the records were analyzed according to the data obtained from extranodular tissues (Table 1). In addition, no correlations were observed between patient age and Allred scores of the samples obtained from nodules and extranodular tissues ( $p=0.359$ and $p=0.959$, respectively).

The pathological examination revealed benign nodules $(n=89,89 \%)$, and papillary $(n=7,7 \%)$, or other cancers (hurtle cell $[n=2,2 \%]$, follicular $[n=1,1 \%]$ and medullary $[n=1,1 \%])$. Mean Allred scores and positivity rates of the samples obtained from the nodules and extranodular tissues in patients with benign nodular disease, papillary cancer, and other cancers were presented in Figures 3 and 4. Allred scores of the benign nodules and papillary cancers were significantly higher than those of the extranodular healthy tissues obtained from the same patients ( $p<0.01$ for both) (Figure 3 ). Likewise, the rate of IGF-1 positivity was significantly higher in benign nodules than in extranodular healthy tissues in the same patients (89.9\% [80/89] vs. 57.3\% [51/89] respectively, $p<0.001)$ (Figure 4$)$. In addition, the Allred scores of papillary cancers $(n=7)$

Table 1. Different variables and Allred 8-unit scores

\begin{tabular}{|c|c|c|c|c|c|c|}
\hline Comparison & Variables & Mean+SD & $\mathrm{p}$ & IGF-1 (+) (\%) & IGF-1 (-) (\%) & $p$ \\
\hline \multirow[t]{3}{*}{ Demographics } & Age & $47.1 \pm 13.5$ & & $47.8 \pm 13.9$ & $42 \pm 9.0$ & $0.16^{\mathrm{a}}$ \\
\hline & Male $(n=16)$ & $50.6 \pm 14.8$ & $0.26^{a}$ & $15(94.8)$ & $1(5.2)$ & $0.685^{\mathrm{b}}$ \\
\hline & Female $(n=84)$ & $46.5 \pm 13.3$ & & 73 (86.9) & $11(13.1)$ & \\
\hline Benign Nodules vs. & Nodules $(n=89)$ & $4.1 \pm 2.3$ & $<0.001^{a}$ & $80(89.9)$ & $9(10.1)$ & $<0.001^{c}$ \\
\hline normal tissue & $\begin{array}{l}\text { Normal Tissue in the same } \\
\text { patient }(n=89)\end{array}$ & $2.3 \pm 2.3$ & & $51(83.1)$ & $38(16.9)$ & \\
\hline Papillary cancer vs. & Papillary cancer $(n=7)$ & $6.7 \pm 1.3$ & $<0.005^{a}$ & $7(100)$ & $0(0)$ & $1.0^{\mathrm{b}}$ \\
\hline normal tissue & $\begin{array}{l}\text { Normal Tissue in the same } \\
\text { patient }(n=7)\end{array}$ & $3.3 \pm 1.9$ & & $6(85.7)$ & $1(14.3)$ & \\
\hline Cancer vs. normal & Cancer $(n=11)$ & $4.9 \pm 3.3$ & $0.08^{\mathrm{a}}$ & $8(72.7)$ & $3(27.3)$ & $0.667^{b}$ \\
\hline tissue & $\begin{array}{l}\text { Normal Tissue in the same } \\
\text { patient }(n=11)\end{array}$ & $2.6 \pm 2.4$ & & $7(63.6)$ & $4(26.4)$ & \\
\hline Benign Nodules vs. & Nodules $(n=89)$ & $4.1 \pm 2.3$ & $<0.005^{a}$ & $80(89.9)$ & $9(10.1)$ & $1.0^{\mathrm{b}}$ \\
\hline papillary cancer & Papillary cancer $(n=7)$ & $6.7 \pm 1.3$ & & $7(100)$ & $0(0)$ & \\
\hline Benign Nodules vs. & Nodules $(n=89)$ & $4.1 \pm 2.3$ & $0.305^{a}$ & $80(89.9)$ & $9(10.1)$ & $0.125^{b}$ \\
\hline cancer & Cancer $(n=11)$ & $4.9 \pm 3.3$ & & $8(72.7)$ & $3(27.3)$ & \\
\hline \multirow[t]{2}{*}{ Hot vs. cold nodules } & Hot nodules $(n=32)$ & $4.4 \pm 2.7$ & $0.57^{a}$ & $28(87.5)$ & $4(22.5)$ & $1.0^{\mathrm{b}}$ \\
\hline & Cold nodules $(n=68)$ & $4.3 \pm 2.3$ & & $60(88.2)$ & $8(21.8)$ & \\
\hline Hyperthyroid vs. & Hyperthyroid $(n=45)$ & $5.0 \pm 2.3$ & $<0.05^{\mathrm{a}}$ & $43(95.6)$ & $2(4.4)$ & $<0.05^{c}$ \\
\hline hypothyroid & Hypothyroid $(n=55)$ & $3.9 \pm 2.7$ & & $45(81.8)$ & $10(18.2)$ & \\
\hline
\end{tabular}




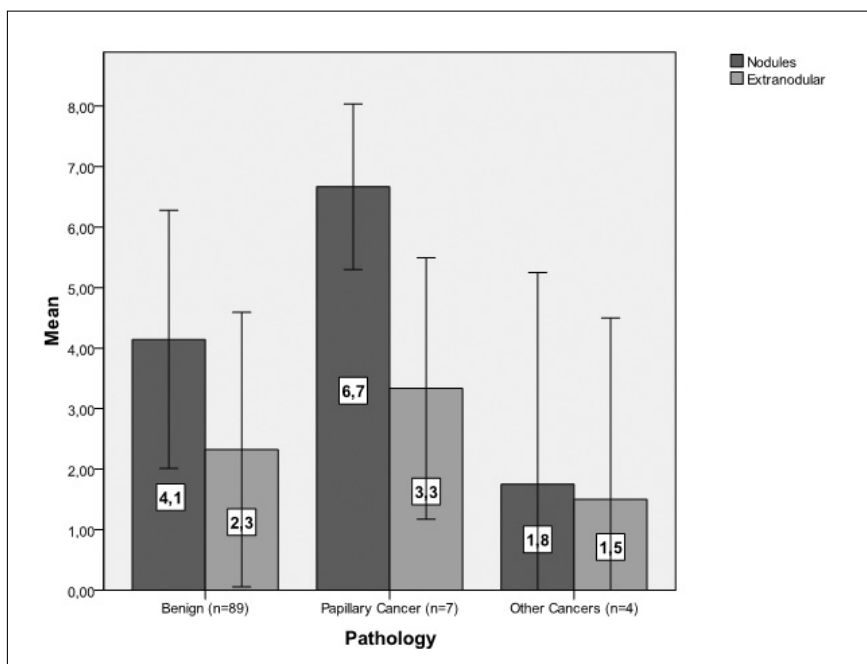

Figure 3. Mean Allred scores of the nodules and extranodular tissues in patients with benign nodular disease, papillary cancer, and other cancers. Mean Allred 8-unit scores were significantly higher in benign nodules $(4.1 \pm 2.3)$ and papillary cancer nodules $(6.7 \pm 1.3)$ than extranodular tissues in the same patients $(2.3 \pm 2.3$ and $3.3 \pm 1.9$, respectively) ( $p<0.001$ and $p<0.005$, respectively). IGF-1 levels were also higher in papillary cancer tissues than in benign nodules $(6.7 \pm 1.3$ vs. $4.1 \pm 2.3, p<0.005)$ There was no statistically significant difference between IGF-1 levels of extranodular tissues obtained from papillary cancer cases and IGF levels of extranodular tissues and IGF levels extranoular tissues obtained from benign cases $(p=0.277)$. (Error bars: $\pm S D)$

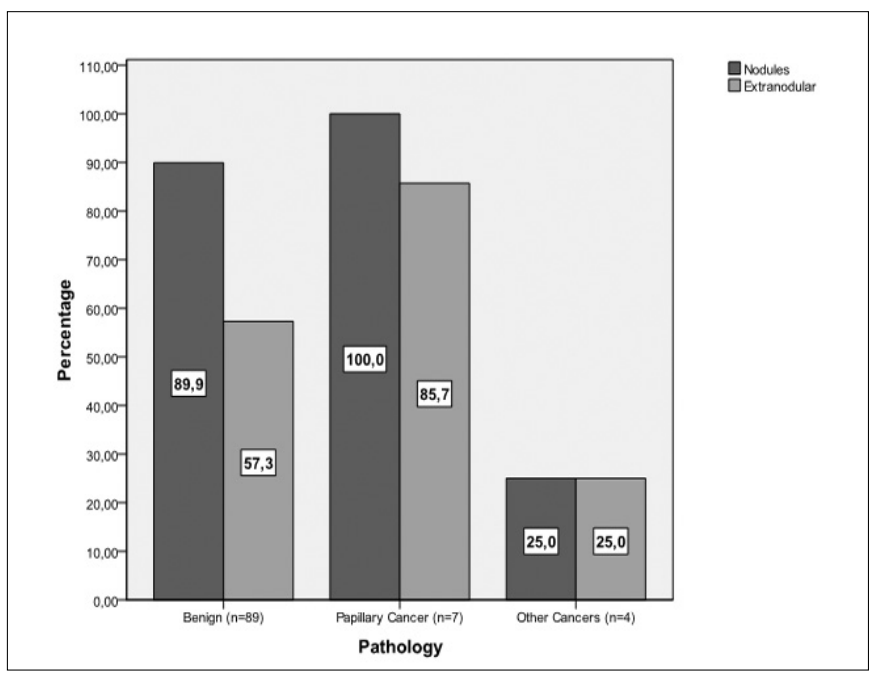

Figure 4. Allred score positivity rates of the samples obtained from the nodules and extranodular tissues in patients with benign nodular disease, papillary cancer, and other cancers. IGF-1 positivity were significantly higher in benign nodules ( $n=89 ; 89.9 \%$ IGF-1 positive) than extranodular tissues in the same patients ( $n=89 ; 57.3 \%$ IGF-1 positive) $(p<0.01)$. No other comparisons were statistically significant

were significantly higher than those of benign nodules $(n=89)$ $(p=0.01)$ (Figure 3). The Allred scores in the malignant nodules was significantly higher than those in extranodular healthy tis- sues taken from all pooled cancer patients $(n=11)(4.9 \pm 3.3$ vs $2.6 \pm 2.4, p=0.08)$

According to scintigraphic examinations, there were 32 hot and 68 cold nodules. Allred scores and IGF-1 positivity rates in the samples taken from the nodules and extranodular healthy tissues were similar within the patients with hot and cold nodules $(4.4 \pm 2.7$ vs. $4.3 \pm 2.3, p=0.57$, and $87.5 \%[28 / 32]$ vs. $88.2 \%$ [60/68], $p=1.0$ [Fisher's exact test] in nodules; $2.4 \pm 2.2$ vs. $2.0 \pm 2.5, p=0.41 ; 84.4 \%$ [27/32] vs. $60.2 \%$ [41/68], $\mathrm{p}=0.522$ in extranodular healthy tissues).

The patients were also classified as hyperthyroid or euthyroid according to the necessity for preoperative antithyroid drug use. A total number of 45 cases were identified as hyperthyroid. Further analysis revealed that Allred scores and IGF-1 positivity rates were significantly higher in hyperthyroid patients than euthyroid cases, when the samples were taken both from the nodules and extranodular healthy tissues $(5.0 \pm 2.3$ vs. $3.9 \pm 2.7, p<0.05 ;$ and $95.6 \%$ [43/45] vs. $81.1 \%$ [45/55], $p<0.05$ in nodules; $2.2 \pm 2.2$ vs. $2.3 \pm 2.5, p=0.836$ and $55.6 \%$ [25/45] vs. $60.0 \%[33 / 55], p=0.688$ in extranodular healthy tissues).

Finally, no correlation was observed between Allred 8 -unit scores of nodules $(4.31 \pm 2.38)$ and volumes of nodules $\left(8.9 \pm 11.7 \mathrm{~cm}^{3}\right)(p=0.778)$, and between Allred 8-unit scores of healthy tissues (mean $=2.29 \pm 2.34$ ) and total thyroid volumes $\left(\right.$ mean $\left.=56.7 \pm 51.7 \mathrm{~cm}^{3}\right)(p=0.971)$.

\section{Discussion}

IGFs are insulin like peptides, two thirds of which are composed of amino acids, and they were isolated in 1970s (5). They promote proliferation, survival and differentiation of cells, and are regulated by growth hormone (6). Although the relationship between IGF levels or positivity and some diseases such as breast cancer has been studied, the effect of IGFs on the development of thyroid diseases is worth analyzing extensively, since IGF-1 receptor and a variety of IGF-binding proteins are expressed in thyroid tissue (8). Experimental investigations have also suggested that IGF-1 may have a role in the development of goiter. An animal study has shown that high levels of IGF-1 concentrations have mitogenic effects in $\mathrm{PC} \mathrm{Cl} 3$ and FRTL-5 cell lines, thereby enlarging the size of thyroid cells (17). Similarly, in a murine model, thyroid enlargement secondary to an increase in follicular elements and decreased blood TSH levels were demonstrated in transgenic mice over-expressing human IGF-1 and IGF-1 receptor (18). The elevation of IGF in diseased human thyroid tissue was first shown by Minuto et al in 1989 (19). They also showed higher concentrations of IGFs in nodules than in normal tissues in patients operated on for nontoxic goiter. Similar results have been reported by others presenting increased tissue-specific IGF-1 concentrations in thyroid diseases (20-22). However, the necessity for a prospective well-designed study with adequate number of patients has been stated for a more accurate analysis of the relationship between IGF and thyroid diseases. As far as we know, current data are the first to assess the proportion and intensity of IGF-1 positivity with a scoring system. Both nodules and healthy tissues in a total number of 100 patients were sampled for Allred 8-unit scores and IGF-1 positivity in this study. 
The current study analyzed the relationship between the demographic data and the tissue levels of IGF-1 in patients with nodular thyroidal diseases. However, both analyses, which were carried out according to sampling locations including nodules and extranodular tissues, failed to reveal a correlation between age and gender, and IGF-1 positivity. In our opinion, IGF-1 positivity is not affected by patients' demographics, but seems to be related to the nature and intensity of the disease. These results were similar to those quoted by Maiarano et al., who denied the presence of a link between the demographic data and the tissue levels of IGF-1 in thyroidal cancer patients (20). Additionally, besides controversial data in the literature, we observed no relationship between the tissue levels of IGF-1 and the volumes of thyroid tissues or nodules $(20,23)$.

In this study, we have investigated the expression level of IGF-1 in nodules and extranodular healthy tissues in patients who underwent total thyroidectomy for nodular thyroidal disease. The proportion and intensity of IGF-1 staining were assessed with 8-unit Allred scoring system, and our data have suggested that the scores and IGF-1 positivity were significantly higher in the samples obtained from benign nodules than those from healthy tissues in the same patient specimens. This finding, reported as high as $66 \%$ to $100 \%$ in previous investigations, supports the proposition that IGF-1 may have a role in the dysfunctional growth of thyroidal cells (19-21).

Our study has also shown higher tissue levels of IGF-1 in nodules than in healthy tissues in the patients with papillary cancer. Cell culture experiments and clinical studies revealed that GH and IGF-1 axis may have a role in neoblastic activity, and overproduction of IGFs act as stimulators of malignant cell proliferation $(7,20,24,25)$. A previous study showed IGF1 positivity in 38 out of 53 patients with thyroidal cancer, and current data confirmed the link between the papillary cancer and elevated tissue levels of IGF-1 (20). In fact, the number of papillary cancer patients $(n=7)$ in our study limited the adequacy of our conclusion, but we still believe that the link between IGF-1 and papillary cancer may be equally or more intense than that between IGF-1 and benign nodules, since our study revealed that IGF-1 levels were also higher in papillary cancer tissues than in benign nodules in other cases. In addition this hypothesis may be strengthened by another exciting finding: the IGF-1 positivity rates and levels were similar in extranodular tissue samplings in patients with benign diseases and with papillary cancers. These data show that the elevated IGF-1 levels do not extend to the comparison of extranodular tissues, so is not related to entire thyroid tissue, but limited to the difference between nodular or cancer tissue samplings. In our opinion, this information is an important result which may confirm the intensity of the link between IGF-1 to papillary cancer, but needs to be analyzed by further high volume studies.

In contrast to the results obtained from the patients with papillary cancer, other types of cancers seem not to have a correlation with the tissue levels of IGF-1. Our study does not expose the cause of this finding, and this may be because of the limited number of the patients in this group $(n=4)$. Chakravarty et al. reported that the expression of IGF-I reseptor in differentiated thyroid cancers was significantly higher than the poorly differentiated thyroid cancers (12).
The relationship between the hyperthyroidism and the tissue levels of IGF-1 has rarely been investigated. Eszlinger et al. have found elevated IGF-1 levels in hot nodules, and suggested that this peptide may play a prominent role for selective growth advantages of hot or cold nodules (26). Our study has revealed no difference in the tissue levels of IGF-1 between hot and cold nodules. However, more importantly, our study has shown that the tissue levels of IGF-1 are higher in hyperthyroid patients. Although elevated tissue levels of IGF-1 have been demonstrated in Graves' disease in previous investigations (27); to our knowledge, our study is the first defining the link between tissue levels of IGF-1 and hyperthyroidism. In our opinion, this is also an important result showing that the effect of elevated tissue levels of IGF-1 levels is not limited to changes of anatomical and histological features, including the development of nodules or papillary cancer, but may also produce some functional outcomes including increased secretion of thyroid hormones.

Current data have some limitations. First, IGF-1 positivity was observed in 58 out of 100 specimens obtained from healthy tissues, lessening the difference between the diseased and normal tissues. This problem not only limits the value of the conclusions of the study, but decreases the possibility of using the tissue levels of IGF-1 as diagnostic tools in thyroid diseases as well. It is unknown, but deserves to be investigated, whether or not IGF-1 levels in healthy thyroid tissues in healthy patients are as high as in healthy tissues neighboring benign or malignant nodules. Secondly, although our study has analyzed 100 patients, there were only 11 cases with thyroid cancer, which limits our conclusions on the relationship between the tissue levels of IGF-1 and malignancy. Thus, our results on malignant tissues need to be validated in a high volume series.

\section{Conclusion}

Our prospective study has shown that IGF-1 levels are higher in nodules than in healthy tissues in the same patients. Similarly, IGF-1 levels are elevated in hyperthyroid patients. These results support the findings of previous studies demonstrating a link between these diseases and IGF-1. In our opinion, these findings may be used in further researches investigating the treatment of benign and malignant thyroidal nodules.

\section{Conflict of Interest}

No conflict of interest was declared by the authors.

\section{References}

1. Gharib H, Papini E. Thyroid nodules: clinical importance, assessment, and treatment. Endocrinol Metab Clin North Am 2007;36:707-35 [CrossRef]

2. Krohn K, Führer D, Bayer Y, Eszlinger M, Brauer V, Neumann S, et al. Molecular Pathogenesis of euthyroid and toxic multinodular goiter. Endocr Rev 2005;26:504-24. [CrossRef]

3. Koh KB, Chang KW. Carcinoma in multinodular goiter. Brit J Surg 1992;79:266-7. [CrossRef] 
4. Bradly DP, Reddy V, Prinz RA, Gattuso P. Incidental papillary carcinoma in patients treated surgically for benign thyroid diseases. Surgery 2009;146:1099-104. [CrossRef]

5. Rinderknecht $E$, Humbel RE. The amino acid sequence of human insulin-like growth factor I and its structural homology with proinsulin. J Biol Chem 1978;253:2769-76.

6. Jones JI, Clemmons DR. Insulin-like growth factors and their binding proteins: biological actions. Endocr Rev 1995;16:3-34. [CrossRef]

7. Schernhammer ES, Holly JM, Hunter DJ, Pollak MN, Hankinson SE. Insulin-like growth factor-l, its binding proteins (IGFBP-1 and IGFBP-3), and growth hormone and breast cancer risk in The Nurses Health Study II. Endocr Relat Cancer 2006;13:583-92. [CrossRef]

8. Van der Laan BF, Freeman JL, Asa SL. Expression of growth factors and growth factor receptors in normal and tumorous human thyroid tissues. Thyroid 1995;5:67-73. [CrossRef]

9. Bechtner G, Schopohl D, Rafferzeder M, Gärtner R, Welsch U. Stimulation of thyroid cell proliferation by epidermal growth factor is different from cell growth induced by thyrotropin or insulin-like growth factor I. Eur J Endocrinol 1996;134:639-48. [CrossRef]

10. Nakahashi K, Kitahori Y, Konishi N, Ohnishi T, Sugimura M, Hiasa Y. Establishment of a rat thyroid carcinoma cell line in vitro demonstrating high DNA synthesis in response to insulin-like growth factor I. Cancer Letters 1996;101:247-55. [CrossRef]

11. Hsiao PJ, Tsai JH. Increased insulin-like growth factor-1 receptors in thyroid tissues of Graves' disease. J Formos Med Assoc 1994;93:925-32.

12. Chakravarty G, Santillan AA, Galer C, Adams HP, El-Naggar AK, Jasser SA, et al. Phosphorylated insulin like growth factor-I receptor expression and its clinico-pathological significance in histologic subtypes of human thyroid cancer. Exp Biol Med (Maywood) 2009;234:372-86. [CrossRef]

13. Maiorano $E$, Ambrosi A, Giorgino R, Fersini M, Pollice L, Ciampolillo A. Insulin-like growth factor 1 (IGF-1) in multinodular goiters: a possible pathogenetic factor. Pathol Res Pract 1994;190:1012-6. [CrossRef]

14. Völzke H, Friedrich N, Schipf S, Haring R, Lüdemann J, Nauck $M$, et al. Association between serum insulin-like growth factor-I levels and thyroid disorders in a population-based study. J Clin Endocrinol Metab 2007;92:4039-45. [CrossRef]

15. Gullu BE, Celik O, Gazioglu N, Kadioglu P. Thyroid cancer is the most common cancer associated with acromegaly. Pituitary 2010;13:242-8. [CrossRef]
16. Allred DC, Clark GM, Elledge R, Fuqua SA, Brown RW, Chamness $\mathrm{GC}$, et al. Association of p53 protein expression with tumor cell proliferation rate and clinical outcome in node-negative breast cancer. J Natl Cancer Inst 1993;85:200-6. [CrossRef]

17. Kimura T, Dumont JE, Fusco A, Golstein J. Insulin and TSH promote growth in size of $\mathrm{PC} \mathrm{Cl3}$ rat thyroid cells, possibly via a pathway different from DNA synthesis: comparison with FRTL-5 cells. Eur J Endocrinol 1999;140:94-103. [CrossRef]

18. Clement S, Refetoff S, Robaye B, Dumont JE, Schurmans S. Low TSH requirement and goiter in transgenic mice overexpressing IGF-I and IGF-Ir receptor in the thyroid gland. Endocrinology 2001;142:131-9. [CrossRef]

19. Minuto F, Barreca A, Del Monte P, Cariola G, Torre GC, Giordano G. Immunoreactive insulin-like growth factor I (IGF-I) and IGF-Ibinding protein content in human thyroid tissue. J Clin Endocrinol Metab 1989;68:621-6. [CrossRef]

20. Maiorano E, Ciampolillo A, Viale G, Maisonneuve P, Ambrosi A, Triggiani $\mathrm{V}$, et al. Insulin-like growth factor 1 expression thyroid tumors. Appl Immunohistochem Mol Morphol 2000;8:110-9. [CrossRef]

21. Maciel RM, Kimura ET, Takahaski MH, Lopes MH, Mesquita MI, Moses AC, et al. Insulin-like growth factor I in human thyroid tissue: specific localization by immunohistochemistry and in situ hybridization. Endocr Pathol 1995;6:207-15. [CrossRef]

22. Vannelli GB, Barni T, Modigliani U. Insulin-like growth factor-I receptors in nonfunctioning thyroid nodules. J Clin Endocrinol Metab 1990;71:1175-82. [CrossRef]

23. Cannavo S, Squadrito S, Finocchiaro MD, Curtò L, Almoto B, Vieni $A$, et al. Goiter and impairment of thyroid function in acromegalic patients: basal evaluation and follow-up. Horm Metab Res 2000;32:190-5. [CrossRef]

24. Yu H, Rohan T. Role of insulin like growth factors family in cancer development and progression. J Natl Cancer Inst 2000;92:1472-89. [CrossRef]

25. Pavelic' K, Spaventi Š, Gluncic' V, Pavici冈 D, Karapandza N, Kusi区 $Z$, et al. The expression and role of insulin like growth factor II in malignant hemangiopericytomas. J Mol Med 1999;77:865-9. [CrossRef]

26. Eszlinger M, Krohn K, Kratzsch J, Voigt C, Paschke R. Growth factor expression in cold and hot thyroid nodules. Thyroid 2001;11:125-35

27. Maiorano E, Perlino E, Triggiani V, Nacchiero M, Giove E, Ciampolillo $A$. Insulin-like growth factor-1 and insulin-like growth factor receptor in thyroid tissues of patients with Graves' disease Int J Mol Med 1998;2:483-6. 